\title{
Tai Chi Therapy Attenuates Biophysiological Status, Pain and Depression in Elderly Subjects
}

\author{
Lisy Joseph ${ }^{1}$, Trichur Venkatakrishnan Ramakrishnan² \\ ${ }^{1}$ Department of Community Health Nursing, Sri Ramachandra Faculty of Nursing, \\ Porur, Chennai, Tamilnadu, India. ${ }^{2}$ Sri Ramachandra Institute of Higher Education \\ and Research, Porur, Chennai, Tamilnadu, India.
}

\section{ABSTRACT}

\section{BACKGROUND}

Tai chi has been widely practiced as a form of art, religious sacrament, a unique technique to relax, work out, and as a method of self-defence for people of all ages. Elderly people and people with chronic illness are more benefited with Tai chi, because of its low intensity, steady rhythm, and low physical and mental tension. This study is planned to determine the effectiveness of Tai chi therapy on biophysiological status and depression among the elderly subjects.

\section{METHODS}

The study was conducted in 150 elderly volunteers of whom 75 were selected for study group and 75 for control group. The 10 forms of Tai chi therapy were demonstrated by the researcher and the same was followed by the participants under supervision. The therapy was performed as one hour session two times in a week for totally twelve weeks under the proper supervision of the researcher. Tai chi therapy was performed following this, by the participants without the supervision of the researcher for 24 weeks as one-hour session twice a week. The total duration of the therapy was 60 minutes which included warm up exercise for 10 minutes, Tai chi therapy 45 minutes and cool down for 5 minutes. The control group received routine care given by the personnel in the old age home. Depression and biophysiological status such as BP, pain and depression were assessed using the questionnaire in both groups at the end of $12^{\text {th }}, 24^{\text {th }}$ and $36^{\text {th }}$ weeks.

\section{RESULTS}

The induction of Tai chi showed significant difference in systolic blood pressure in elderly who practiced Tai chi therapy. The independent $t$ test value was found to be as follows-pre-test: $1.837(\mathrm{p}=0.068)$, post-test I: $2.858(\mathrm{p}=0.005)$, post-test II: 3.723 $(p=0.000)$ and post-test III: $3.737(p=0.000)$. In pain evaluation it was noted that $t-$ test for pre-test : $1.712(\mathrm{p}=0.089)$, post-test I: $2.514(\mathrm{p}=0.13)$, post-test II: 3.836 (p $=0.000)$ and post-test III: $4.502(\mathrm{p}=0.000)$. Thus, it is evident that Tai chi therapy was useful in managing pain. In view of depression, it was noted that Tai chi therapy was also little effective as seen by the t test values, pre-test: $0.441(p=0.660)$, posttest I: 1.458 ( $\mathrm{p}=0.147)$, post-test II: $1.693(\mathrm{p}=0.032)$ and post-test III: 2.787 ( $\mathrm{p}=$ 0.006).

\section{CONCLUSIONS}

It was evident that Tai chi therapy is very effective in elderly people. There were significant changes in biophysiological status, depression and pain in the elderly who received Tai chi therapy.

\section{KEY WORDS}

Elderly, Pain, Depression, Tai Chi Therapy
Corresponding Author:

Dr. Lisy Joseph,

Department of Community Health Nursing,

Sri Ramachandra Faculty of Nursing,

Porur, Chennai, Tamilnadu, India.

E-mail: lisyjoseph@sriramachandra.edu.in

DOI: $10.14260 /$ jemds/2021/21

How to Cite This Article:

Joseph L,Ramakrishnan TV. Tai chi therapy attenuates biophysiological status, pain and depression in elderly subjects. J Evolution Med Dent Sci 2021;10(02):102106, DOI: $10.14260 /$ jemds/2021/21

Submission 21-09-2020,

Peer Review 13-11-2020,

Acceptance 20-11-2020,

Published 11-01-2021.

Copyright (C) 2021 Lisy Joseph et al. This is an open access article distributed under Creative Commons Attribution License [Attribution 4.0 International (CC BY 4.0)] 


\section{BACKGROUND}

The life expectancy of older people continues to rise in India. Majority of the world's population consist of people of age above 60 years as most people are expected to live beyond this, and thus population is increasing day by day and it is expected now, that this will be around 5 billion. ${ }^{1}$ People are not healthier now when compared to olden days though they live longer than before. The concern for today is that whether the additional years living beyond will comprise good number of years of healthy life and promote a high health-related quality of life into old age. Healthy life is supported with physical activity, which encompasses sports and ground exercise which is performed as part of daily activity, occupation, leisure, or active transportation. ${ }^{2}$ It is a protective factor for noncommunicable diseases such as cardiovascular disease, stroke, diabetes, and it is also associated with improved mental health, delay in the onset of dementia and improved quality of life and wellbeing. ${ }^{3}$ As a result of the aging process, elders typically experience declining physical functioning and increasing incidence of chronic health problems, which often affect their sense of well-being and lower their quality of life and self-satisfaction. Although some declines with age are inevitable, research indicates that physically active older adults maintain healthy functioning as a normal process. ${ }^{4}$ Lot of research is going on to understand the benefit of exercise and its outcome under various disciplines. The beneficial effects of exercise on an elder's well-being, both physical and psychologic, have been already reported. ${ }^{5}$

Tai chi has been widely practiced as a form of art, religious sacrament, an unique technique to relax, stress buster, rejuvenate, work out, and method of self-defence for people of all ages. ${ }^{6}$ It includes a flow of liquid in body, consistent, elegant, move like developments that are incorporated by mind fixation, balance, moving of body weight, muscle unwinding, and breathing control. ${ }^{7}$ As it doesn't put much stress on muscles and joints it is considered to be safe for people of all ages. Individuals of a similar biological age may exhibit a wide variance in their responses to exercise because of varying aging processes. ${ }^{8}$ The need for Tai-Chi exercise should be personalized with regard to the intensity and difficulty, and exercise levels should gradually progress based on the functional ability of the individuals who can perform the exercise. ${ }^{9}$ It is also reported that Tai chi exercise may provide psychological benefits, such as enhanced positive mood states and reduced nightmares.

Tai chi is more effective for elder people who have suffered a stroke, heart attack or other ailment, the benefits can greatly enhance quality of life. It reduces stress, increases oxygen flow, enhances mental capacity and concentration, reduces blood pressure, alleviates pain and improves posture balance. ${ }^{10}$ Studies reported that when a person practices Tai chi with full mind concentration, enhanced and peaceful breathing in every movement, the person will experience relaxation in mind thus leading to many additional benefits to the body. ${ }^{11}$ In general, Tai chi has been shown to produce stability, fall prevention, cardiovascular and ventilatory enhancement, health-related fitness improvement, rheumatoid arthritis rehabilitation, and pain, stress, and nightmare reduction. Researchers also found that Tai chi practitioners had better physical and mental health status, lower systolic and diastolic blood pressure, fewer falls within a year, less mood disturbance, and better mood status when compared with people who didn't practice the exercise. ${ }^{12}$ Tai chi can be incorporated into community programs or senior centre activities to promote the wellbeing of community-dwelling elders. It also could be included as an activity in nursing homes, community centres and rehabilitation programs in hospital settings. ${ }^{13}$

In India, though a lot of natural therapies are available and practiced by many, Tai chi is not greatly practiced. There is a great need for this therapy to be followed for the elderly people as this therapy showed a lot of potential benefits. Thus, this study is planned to determine the effectiveness of Tai chi therapy on biophysiological status and depression among the residing elderly subjects.

\section{METHODS}

A quantitative quasi experimental research with evaluative approach was used and the study was approved by the institutional ethics committee of Sri Ramachandra University, Chennai. The study was conducted from January 2013 to July 2014 and each elderly participated in the study for a duration of nine months period. It was conducted to evaluate the effectiveness of Tai chi therapy, in relation to biophysiological status and depression among the elderly. The sample size was 68 in each group with a total of 136 to achieve $80 \%$ power at a $5 \%$ level of significance. Considering $10 \%$ of attrition the total was rounded to 150 of whom 75 elderly were selected for study group and 75 for control group by random sampling method. Inclusion criteria were males and females from old age home, aged between $60-80$ yrs., willing to participate, able to understand Tamil and English, able to walk, stand, move both upper and lower limbs without support. Participants with psychiatric, systemic illness, loss of vision, hearing issues, stay of less than 3 months at old age home and who had undergone surgeries were excluded. After proper permissions, 32 old age homes were contacted, 8 homes gave permission to assess, in which 2 homes had only female residents and one home was government run home. Due to difficulties in comparison these 3 homes were excluded and 5 homes were selected. From the remaining 5, two homes with maximum number of inmates which were comparable in terms of number of residents, both sexes, facilities like food, recreation and health care provided free of cost were selected to meet the sample size. Out of 2 homes one home was allotted as study group and one home as control group by simple randomisation. Upon providing adequate information, informed consent was obtained from all participants. The study was conducted from January 2013 to July 2014 and each elderly participated in the study for a duration of nine months period. Pre-test assessment was done for all the participants in both study and control group. It includes information of background variables like demographic, personal and clinical data. Depression was assessed using Geriatric Depression Scale. The data was collected in the form of questionnaire. Tai chi therapy was taught to all participants in the study group, 25 in each group. The 10 forms of Tai chi therapy (Starting form, Grasp peacock's tail, single whip, white crane spreads its wings, raise hands and push up, left knee brush, right knee brush, apparent close up, crossed hand and finishing form) was demonstrated by the researcher and the same was followed by the participants under supervision. The therapy 
was performed as one hour session twice a week for 12 weeks under the supervision of the researcher. Following this the Tai chi therapy was performed by the participants without the supervision of the researcher for 24 weeks as one-hour session twice a week. The researcher visited the old age home once a week and provided reinforcement to the participants. The total duration of the therapy was 60 minutes which constitutes warm up exercise for 10 minutes, Tai chi therapy 45 minutes and cool down for 5 minutes. The control group received routine care given by the personnel in the old age home. Depression and bio physiological status such as BP and pain were assessed using the questionnaire in both groups at the end of $12^{\text {th }}, 24^{\text {th }}$ and $36^{\text {th }}$ weeks. Post-test I was for the participants in the study and control group at the end of 12 weeks, post-test II is at 24 weeks and post-test III is for 36 weeks. The questionnaire used was the same all through the post-tests. The investigator ensured confidentiality of all the participants.

\section{Ethical Considerations}

An approval to conduct study was obtained from the institutional ethical committee, Sri Ramachandra University.

\section{Statistical Analysis}

Data was analysed using the SPSS for windows (version 17) and $p$ value of $<.05$ was considered significant. To compare the observations within the group paired ' $\mathrm{t}$ ' test was used. To compare the relationship between the groups independent ' $\mathrm{t}$ ' test was used.

\section{RESULTS}

\begin{tabular}{|c|c|c|c|c|c|c|}
\hline \multirow[t]{2}{*}{$\begin{array}{c}\text { Level of Systolic Blood } \\
\text { Pressure }\end{array}$} & \multicolumn{2}{|c|}{$\begin{array}{l}\text { Pretest } \\
(n=75)\end{array}$} & \multicolumn{2}{|c|}{ 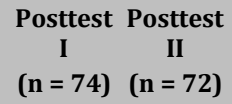 } & \multicolumn{2}{|c|}{$\begin{array}{c}\text { Posttest } \\
\text { III } \\
(n=70)\end{array}$} \\
\hline & No & $\%$ & No. $\%$ & No. $\%$ & No. & $\%$ \\
\hline Normal $<130 \mathrm{~mm}$ of $\mathrm{Hg}$ & 20 & 26.7 & $24 \quad 32.4$ & $26 \quad 36.2$ & 26 & 37.1 \\
\hline $\begin{array}{c}\text { Pre Hypertension } 130-139 \mathrm{mI} \\
\mathrm{Hg}\end{array}$ & 16 & 21.3 & $16 \quad 21.6$ & 20.8 & 20 & 28. \\
\hline Stage 1 (Mild) $140-159 \mathrm{~mm}$ of $\mathrm{Hg}$ & 28 & 37.3 & $25 \quad 33.8$ & $25 \quad 34.7$ & 20 & 28.6 \\
\hline $\begin{array}{c}\text { Stage 2(Moderate) } 160-179 \mathrm{~mm} \text { of } \\
\mathrm{Hg}\end{array}$ & 10 & 13.3 & $08 \quad 10.8$ & $06 \quad 8.3$ & 04 & 5.7 \\
\hline Stage 3 (Severe) > $180 \mathrm{~mm}$ of $\mathrm{Hg}$ & 01 & 1.4 & $01 \quad 1.4$ & 00 & 00 & - \\
\hline $\begin{array}{l}\text { Table 1. Frequency and Per } \\
\text { ressure during Pre-Test, Pos }\end{array}$ & 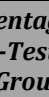 & $n$ & ihuti & f Sucto & & \\
\hline
\end{tabular}

\begin{tabular}{|c|c|c|c|c|c|c|}
\hline \multirow{2}{*}{$\begin{array}{l}\text { Duration } \\
\text { of the Study }\end{array}$} & \multicolumn{2}{|c|}{ Study Group } & \multicolumn{2}{|c|}{ Control Group } & \multirow{2}{*}{$\begin{array}{c}\text { Mean } \\
\text { Difference }\end{array}$} & \multirow{2}{*}{$\begin{array}{c}\text { Independent } \\
\text { t \& p Value }\end{array}$} \\
\hline & Mean & SD & Mean & SD & & \\
\hline Pretest a,b & 149.84 & 18.142 & 150.81 & 19.329 & -097 & $\begin{array}{c}1.837 \\
.068 \mathrm{NS}\end{array}$ \\
\hline Posttest $1^{c, d}$ & 147.59 & 17.114 & 149.71 & 19.595 & 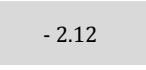 & \\
\hline Posttest II ${ }^{e, f}$ & 143.44 & 16.425 & 149.34 & 20.048 & -5.9 & $\begin{array}{c}3.723 \\
.000^{* * *}\end{array}$ \\
\hline Posttest IIIgh & 141.77 & 16.780 & 148.67 & 19.531 & -6.9 & $\begin{array}{c}3.737 \\
.000^{* * *}\end{array}$ \\
\hline
\end{tabular}

Table 2. Comparison of Pre-Test, Post-Test I, Post-Test II and Post-Test III Mean Score of Systolic Blood Pressure among Elderly between the Study and the Control Groups $(N=150)$

NS- Non-Significant, ${ }^{* * *} \mathrm{p}<.001{ }^{* *} \mathrm{p}<.01$, a $\mathrm{n}=75,{ }^{\mathrm{c}} \mathrm{n}=74$, e $\mathrm{n}=72, \mathrm{~g} \mathrm{n}=70$ for the study group, ${ }^{\mathrm{b}} \mathrm{n}=75,{ }^{\mathrm{d}} \mathrm{n}=75,{ }^{\mathrm{f}} \mathrm{n}=71,{ }^{\mathrm{h}} \mathrm{n}=69$ for the control group.
Table 1 projects the distribution of systolic blood pressure among the elderly in the study group. During pre-test 20 (26.7 $\%$ ) elderly had normal systolic blood pressure which has been improved to 26 (37.1\%) in the post-test III and 28 (37.3\%) had mild systolic hypertension during pre-test which has been reduced to $20(28.6 \%)$ in the post-test III.

Table 2 represents level of systolic blood pressure among elderly between the study and control groups. During the pretest, post-test I, II and III it was noted that there was no difference between the groups. The total number of attrition of elderly in this study was 11 . Two elderly in the study group and four elderly in the control group left the old age home, one elderly in the study group and two in the control group died and 2 elderly in the study group became sick, during the period of study.

\begin{tabular}{|c|c|c|c|c|c|c|}
\hline \multirow{2}{*}{\begin{tabular}{|c} 
Duration of \\
Study
\end{tabular}} & \multicolumn{2}{|c|}{ Study Group } & \multicolumn{2}{|c|}{ Control Group } & \multirow{2}{*}{$\begin{array}{c}\text { Mean } \\
\text { Difference }\end{array}$} & \multirow{2}{*}{$\begin{array}{c}\text { Independent } \\
\text { t \& p Value }\end{array}$} \\
\hline & Mean & SD & Mean & SD & & \\
\hline Pretest $\mathrm{a}, \mathrm{b}$ & 88.45 & 10.065 & 87.67 & 11.321 & 0.78 & $\begin{array}{c}0.989 \\
.324 \mathrm{NS}\end{array}$ \\
\hline Posttest $1 \mathrm{c,d}$ & 86.22 & 10.319 & 88.43 & 11.867 & -2.21 & $\begin{array}{c}1.176 \\
.242 \mathrm{NS}\end{array}$ \\
\hline Posttest II $\mathrm{e}^{\mathrm{e}} \mathrm{f}$ & 85.86 & 9.526 & 88.61 & 12.010 & -2.75 & $\begin{array}{c}0.065 \\
.972 \mathrm{NS}\end{array}$ \\
\hline Posttest IIIgh & 85.44 & 10.123 & 88.72 & 11.620 & -3.28 & $\begin{array}{l}0.021 \\
.032^{*} \\
\end{array}$ \\
\hline \multicolumn{7}{|c|}{$\begin{array}{l}\text { Table 3. Comparison of Pre-Test, Post-Test I, Post-Test II and Post-Test } \\
\text { III Mean Score of Diastolic Blood Pressure among Elderly between the } \\
\text { Study and the Control Groups }(N=150)\end{array}$} \\
\hline $\begin{array}{l}\text { NS- Non signi } \\
=75, \mathrm{~d} n=75,\end{array}$ & $\begin{array}{l}\text { nt, }{ }^{*} p \\
71, \text { h }\end{array}$ & $\begin{array}{l}a n= \\
9 \text { for }\end{array}$ & $\begin{array}{l}n=74 \\
\text { ontro }\end{array}$ & $\begin{array}{l}=72 \text {, } \\
\text { up. }\end{array}$ & $1=70$ for $t h$ & study group, ${ }^{\mathrm{b}} \mathrm{n}$ \\
\hline
\end{tabular}

Table 3 highlighted the mean difference between the diastolic blood pressure among the study and the control groups during the pretest and posttests. It was identified that during pre-test, post-test I and post-test II there was no significant mean difference between the study and control groups. At post-test III, a statistically significant mean difference was identified between the study and the control groups at $\mathrm{p}<.05$ level of significance.

\begin{tabular}{|c|c|c|c|c|c|c|}
\hline \multirow{2}{*}{$\begin{array}{c}\text { Duration of } \\
\text { Study }\end{array}$} & \multicolumn{2}{|c|}{ Study Group } & \multicolumn{2}{|c|}{ Control Group } & \multirow{2}{*}{$\begin{array}{c}\text { Mean } \\
\text { Difference }\end{array}$} & \multirow{2}{*}{$\begin{array}{c}\text { Independent t } \\
\& \\
\text { p Value }\end{array}$} \\
\hline & Mean & SD & Mean & SD & & \\
\hline Pretest $\mathrm{a}, \mathrm{b}$ & 4.25 & 1.685 & 4.01 & 2.193 & 0.24 & $\begin{array}{c}1.712 \\
.089 \mathrm{NS}\end{array}$ \\
\hline Posttest $1 \mathrm{c,d}$ & 3.97 & 1.688 & 3.83 & 2.166 & 0.14 & $\begin{array}{l}2.514 \\
.013^{*}\end{array}$ \\
\hline Posttest II $\mathrm{e}, \mathrm{f}$ & 3.21 & 1.661 & 3.22 & 2.112 & -0.01 & $\begin{array}{l}3.836 \\
.003^{* *}\end{array}$ \\
\hline Posttest IIIg,h & 2.47 & 1.726 & 3.57 & 2.074 & -1.10 & $\begin{array}{c}4.502 \\
.000^{* * *}\end{array}$ \\
\hline \begin{tabular}{|} 
Table 4. Com \\
III Mean S
\end{tabular} & $\begin{array}{l}\text { npariso } \\
\text { Score o }\end{array}$ & $\begin{array}{l}\text { of Pre } \\
\text { Pain ar } \\
\text { Cont }\end{array}$ & $\begin{array}{l}\text { Test, Pos } \\
\text { ong Eld } \\
\text { ol Groul }\end{array}$ & $\begin{array}{l}\text { t-Test I } \\
\text { erly bet } \\
s(N=1\end{array}$ & $\begin{array}{l}\text { I, Post-Test I } \\
\text { tween the St } \\
\text { 150) }\end{array}$ & $\begin{array}{l}\text { II and Post-Test } \\
\text { tudy and the }\end{array}$ \\
\hline
\end{tabular}

Table 4 compares the mean and standard deviation of the pain scores between the study and the control groups during pre-test and post-tests I, II \& III. A statistically significant difference in the mean scores was identified during the posttest I at $\mathrm{p}<.05$, post-test II at $\mathrm{p}<.01$ and post-test III at $\mathrm{p}<$ .001 between the study and the control groups. Table 5 compares the mean and standard deviation of the depression scores between the study and the control groups during pretest and post-tests I, II \& III. A statistically significant difference in the mean score was identified during the post-test II at $\mathrm{p}<$ 
.05 and post-test III at $\mathrm{p}<.01$ between the study and the control groups.

\begin{tabular}{|c|c|c|c|c|c|c|}
\hline \multirow{2}{*}{$\begin{array}{c}\text { Duration of } \\
\text { Study }\end{array}$} & \multicolumn{2}{|c|}{ Study Group } & \multicolumn{2}{|c|}{ Control Group } & \multirow{2}{*}{$\begin{array}{c}\text { Mean } \\
\text { Difference }\end{array}$} & \multirow{2}{*}{$\begin{array}{l}\text { Independent } \\
\text { t \& p Value }\end{array}$} \\
\hline & Mean & SD & Mean & SD & & \\
\hline Pretest a,b & 16.52 & 2.910 & 15.72 & 2.633 & 0.80 & $\begin{array}{l}0.441 \\
.660 \mathrm{NS}\end{array}$ \\
\hline Posttest $1^{c, d}$ & 15.19 & 3.051 & 15.85 & 2.486 & -0.66 & $\begin{array}{c}1.458 \\
.147 \mathrm{NS}\end{array}$ \\
\hline Posttest II $\mathrm{e}, \mathrm{f}$ & 14.06 & 3.103 & 14.87 & 2.651 & -0.81 & $\begin{array}{l}1.693 \\
.032 *\end{array}$ \\
\hline Posttest IIIg,h & 12.74 & 3.238 & 15.17 & 2.797 & -2.43 & $\begin{array}{l}2.787 \\
.006^{* *} \\
\end{array}$ \\
\hline \multicolumn{7}{|c|}{$\begin{array}{l}\text { Table 5. Comparison of Pre-Test, Post-Test I, Post-Test II and Post-Test } \\
\text { III Mean Score of Depression among Elderly between the Study and the } \\
\text { Control Groups }(N=150)\end{array}$} \\
\hline $\begin{array}{r}\text { NS - Non-Signi } \\
\text { gr }\end{array}$ & $\mathrm{t},{ }^{*} \mathrm{p}$ & ${ }^{* *} \mathrm{p}$ & 01 a $n=$ & $\mathrm{c} n=74$ & $\begin{array}{l}\text { t, } \mathrm{e} \mathrm{n}=72, \mathrm{~g} \mathrm{n}=7 \\
\text { the control gro }\end{array}$ & $\begin{array}{l}70 \text { for the study } \\
\text { oup. }\end{array}$ \\
\hline
\end{tabular}

\section{DISCUSSION}

Tai chi aims to strengthen, stretch, balance, and coordinate and integrate the left and right halves of the body, the upper and lower halves of the body, and the extremities of the body with the inside or core. ${ }^{14}$ The body movements in Tai chi are coordinated with rhythmic, conscious breathing and multiple cognitive and emotional components-including visualization, focused attention, imagery, heightened self-awareness, and intention. 15

The present study is conducted first, to evaluate the impact of Tai chi influence of bio physiological status, depression and quality of life in elderly subjects. Lifestyle modifications such as regular exercise and a healthy diet are other factors that have been shown to bring positive changes during the aging process. Various studies have associated exercise with improved health in older adults, but most studies have focused on vigorous, high-intensity exercise. ${ }^{16}$

It has been reported that medium intensity aerobic exercise yields promising outcomes in the process of prevention and recuperation among elderly patients. Tai chi exercise involves a slow movement of the body structure and joints. ${ }^{17}$ Previous studies have shown that long-term Tai chi practice shows some encouraging effects by controlling the balance, cardiovascular fitness, flexibility, and reduced risk of falls in elderly patients. ${ }^{18} \mathrm{In}$ another study it was noted that Tai chi benefited high blood pressure in elderly patients. It was noted in our study that Tai chi therapy benefited patients with high blood pressure. ${ }^{19} \mathrm{On}$ induction of Tai chi therapy to the elderly people, a significant improvement is seen in the frequency and percentage distribution of the systolic blood pressure. $^{20}$

The mechanism of change in blood pressure maybe contributed to loss of sodium in perspiration during exercise where sodium losses may exceed normal dietary intake. In addition, the decreased tonic sympathetic nerve activity produced by exercise training can be considered as one of the mechanisms involved in the attenuation of hypertension which is very evident in our study. The reductions on sympathetic drive that follow training are more pronounced in patients with essential hypertension than in normotensive individuals and are likely to underline the antihypertensive effect of exercise. ${ }^{21}$ There are other proposed mechanisms accounting for the antihypertensive effects of exercise training; the decrease of plasma norepinephrine, decrease of endogenous ouabain-like substance, increase of prostaglandin $\mathrm{E}$, or decrease of plasma renin activity were also proposed to play a role. ${ }^{22}$

In one study, the effect of Tai chi was studied on the depressive symptoms of patients. It was noted that three months of Tai chi intervention can significantly reduce scores on the Center for Epidemiological Studies Depression Scale. ${ }^{23}$ In another study selective serotonin reuptake inhibitor (SSRI)(escitalopram) treatment supplemented with Tai chi, the subjects were more likely to experience a greater improvement in depressive symptoms and achieve depression remission. ${ }^{24}$ These findings suggest that supplementing pharmacologic treatment with Tai chi may yield greater clinical improvement for individuals with geriatric depression. Studies have shown that depression is linked to structural and functional abnormalities in brain regions that are associated with emotion processing, self-representation, reward, and external stimulus interactions. Studies also suggest that core components of mind-body interventions such as Tai chimay include attentional control emotion regulation, and selfawareness. ${ }^{25}$ In our study it was noted that depression scores drastically improved after Tai chi intervention which is evident as mentioned in clinical trials. ${ }^{26}$ Severe depression among old age group was found more in affluent areas and old age homes. Thus, the intervention of Tai chi is a boon to such old people which will influence their life for their good and wellbeing.

\section{CONCLUSIONS}

The elderly residing at old age homes have significant changes in the biophysiological status. Tai chi therapy offers a safe, non-pharmacological approach to enhance the well-being among elderly. Elderly who received Tai chi therapy had significant reduction in their biological status such as systolic blood pressure and diastolic blood pressure. Highly significant reductions in the pain and depression scores were observed among the elderly who received Tai chi therapy. Thus, Tai chi therapy is an effective therapy in maintaining the physical and psychological wellbeing of the elderly.

Data sharing statement provided by the authors is available with the full text of this article at jemds.com.

Financial or other competing interests: None.

Disclosure forms provided by the authors are available with the full text of this article at jemds.com.

\section{REFERENCES}

[1] Chatterji S, Byles J, Cutler D, et al. Health, functioning and disability in older adults--present status and future implications. Lancet 2015;385(9967):563-75.

[2] Langhammer B, Bergland A, Rydwik E. The importance of physical activity exercise among older people. Biomed Res Int2018;2018:7856823.

[3] Das P, Horton R. Rethinking our approach to physical activity. Lancet2012;380(9838):189-90.

[4] Charles ST, Carstensen LL. Social and emotional aging. Annu Rev Psychol2010;61:383-409. 
[5] Delle Fave A, Bassi M, Boccaletti ES, et al. Promoting wellbeing in old age: the psychological benefits of two training programs of adapted physical activity. Front Psychol2018;9:828.

[6] Young DR, Appel LJ, Jee S, et al. The effects of aerobic exercise and T'ai chi on blood pressure in older people: results of a randomized trial. J Am Geriatr Soc 1999;47(3):277-84.

[7] Song QH, Zhang QH, Xu RM, et al. Effect of tai-chi exercise on lower limb muscle strength, bone mineral density and balance function of elderly women. Int J Clin Exp Med 2014;7(6):1569-76.

[8] Booth FW, Roberts CK, Laye MJ. Lack of exercise is a major cause of chronic diseases. ComprPhysiol 2012;2(2):1143211.

[9] Penn I, Sung W, Lin C. Effects of individualized Tai-chi on balance and lower-limb strength in older adults. BMC Geriatr 2019;19(1):235.

[10] Lan C, Chen SY, Lai JS, et al. Tai chi chuan in medicine and health promotion. Evid Based Complement Alternat Med 2013;2013:502131.

[11] Robins JL, Elswick RK, McCain NL. The story of the evolution of a unique tai chi form: origins, philosophy and research. J Holist Nurs 2012;30(3):134-46.

[12] Hosseini L, Kargozar E, Sharifi F, et al. Tai chi Chuan can improve balance and reduce fear of falling in community dwelling older adults: a randomized control trial. J ExercRehabil 2018;14(6):1024-31.

[13] Stevens JA, Voukelatos A, Ehrenreich H. Preventing falls with tai ji quan: a public health perspective. J Sport Health Sci 2014;3(1):21-6.

[14] Hackney ME, Wolf SL. Impact of tai chi Chu'anpractice on balance and mobility in older adults: an integrative review of 20 years of research. J Geriatr Phys Ther 2014;37(3):127-35.

[15] Yang GY, Wang LQ, Ren J, et al. Evidence Base of clinical studies onTai chi: a bibliometric analysis. PLoS One 2015;10(3):e0120655.
[16] McPhee JS, French DP, Jackson D, et al. Physical activity in older age: perspectives for healthy ageing and frailty. Biogerontology 2016;17(3):567-80.

[17] Jahnke R, Larkey L, Rogers C, et al. A comprehensive review of health benefits of qigong and tai chi. Am J Health Promot 2010;24(6):e1-e25.

[18] Rogers CE, Larkey LK, Keller C. A review of clinical trials of tai chi and qigong in older adults. West J Nurs Res 2009;31(2):245-79.

[19] Abbott R, Lavretsky H. Tai chi and Qigong for the treatment and prevention of mental disorders. Psychiatr Clin North Am 2013;36(1):109-19.

[20] Tai HC, Chou YS, Tzeng IS, et al. Effect of tai chi synergy T1 exercise on autonomic function, metabolism and physical fitness of healthy individuals. Evid Based Complement Alternat Med 2018;2018:6351938.

[21] O'Sullivan SE, Bell C. The effects of exercise and training on human cardiovascular reflex control. J AutonNervSyst 2000;81(1-3):16-24.

[22] Kargarfard M, Rouzbehani R, Basati F. Effects of exercise rehabilitation on blood pressure of patients after myocardial infarction. Int J Prev Med 2010;1(2):124-30.

[23] Kong J, Wilson G, Park J, et al. Treating depression with tai chi: state of the art and future perspectives. Front Psychiatry 2019;10:237.

[24] Lavretsky H, Alstein LL, Olmstead RE, et al. Complementary use of tai chi chih augments escitalopram treatment of geriatric depression: a randomized controlled trial. Am J Geriatr Psychiatry 2011;19(10):839-50.

[25] Wahbeh H, Elsas SM, Oken BS. Mind-body interventions: applications in neurology. Neurology 2008;70(24):23218.

[26] Laird KT, Paholpak P, Roman M, et al. Mind-body therapies for late-life mental and cognitive health. Curr Psychiatry Rep 2018;20(1):2. 